\title{
Aboveground biomass in Inner Mongolian temperate grasslands decreases under climate warming
}

Guocheng Wang et al. 
Table S1. The environmental covariates used in this study.

\begin{tabular}{|c|c|c|c|}
\hline Covariates & Code & Description & Unit \\
\hline \multirow[t]{10}{*}{ Edaphic variables } & CFRAG & Coarse fragments $(>2 \mathrm{~mm})$ & $\%$ \\
\hline & BULK & Bulk density & $\mathrm{g} \mathrm{cm}^{-3}$ \\
\hline & ORGC & Organic carbon & $\mathrm{g} \mathrm{kg}^{-1}$ \\
\hline & SDTO & Sand content & $\%$ \\
\hline & CLPC & Clay content & $\%$ \\
\hline & STPC & Silt content & $\%$ \\
\hline & TAWC & Available water capacity & $\mathrm{cm} \mathrm{m}^{-1}$ \\
\hline & TOTN & Total nitrogen & $\mathrm{g} \mathrm{kg}^{-1}$ \\
\hline & $\mathrm{CNrt}$ & $\mathrm{C}: \mathrm{N}$ ratio & - \\
\hline & PHAQ & $\mathrm{pH}$ measured in $\mathrm{H}_{2} \mathrm{O}$ & - \\
\hline \multirow[t]{23}{*}{ Climatic variables } & $\mathrm{T} 1$ & Annual mean temperature & ${ }^{\circ} \mathrm{C}$ \\
\hline & $\mathrm{T} 2$ & Mean diurnal range & ${ }^{\circ} \mathrm{C}$ \\
\hline & $\mathrm{T} 3$ & Isothermality $(\mathrm{T} 2 / \mathrm{T} 7 \times 100)$ & $\%$ \\
\hline & $\mathrm{T} 4$ & Temperature seasonality (standard deviation×100) & ${ }^{\circ} \mathrm{C}$ \\
\hline & T5 & Max temperature of warmest month & ${ }^{\circ} \mathrm{C}$ \\
\hline & T6 & Min temperature of coldest month & ${ }^{\circ} \mathrm{C}$ \\
\hline & $\mathrm{T} 7$ & Temperature annual range (T5-T6) & ${ }^{\circ} \mathrm{C}$ \\
\hline & $\mathrm{T} 8$ & Mean temperature of wettest quarter & ${ }^{\circ} \mathrm{C}$ \\
\hline & T9 & Mean temperature of direst quarter & ${ }^{\circ} \mathrm{C}$ \\
\hline & $\mathrm{T} 10$ & Mean temperature of warmest quarter & ${ }^{\circ} \mathrm{C}$ \\
\hline & $\mathrm{T} 11$ & Mean temperature of coldest quarter & ${ }^{\circ} \mathrm{C}$ \\
\hline & P1 & Annual precipitation & $\mathrm{mm}$ \\
\hline & $\mathrm{P} 2$ & Precipitation of wettest month & $\mathrm{mm}$ \\
\hline & P3 & Precipitation of driest month & $\mathrm{mm}$ \\
\hline & P4 & Precipitation seasonality (coefficient of variation) & $\%$ \\
\hline & P5 & Precipitation of wettest quarter & $\mathrm{mm}$ \\
\hline & P6 & Precipitation of driest quarter & $\mathrm{mm}$ \\
\hline & P7 & Precipitation of warmest quarter & $\mathrm{mm}$ \\
\hline & P8 & Precipitation of coldest quarter & $\mathrm{mm}$ \\
\hline & MATG & Mean annual temperature during growing season & ${ }^{\circ} \mathrm{C}$ \\
\hline & MATNG & Mean annual temperature during non-growing season & ${ }^{\circ} \mathrm{C}$ \\
\hline & MAPG & Mean annual precipitation during growing season & $\mathrm{mm}$ \\
\hline & MAPNG & Mean annual precipitation during non-growing season & $\mathrm{mm}$ \\
\hline Grassland type & - & Meadow, typical and desert steppe & - \\
\hline Livestock & - & Cattle, sheep and goat & head $\mathrm{km}^{-2}$ \\
\hline
\end{tabular}




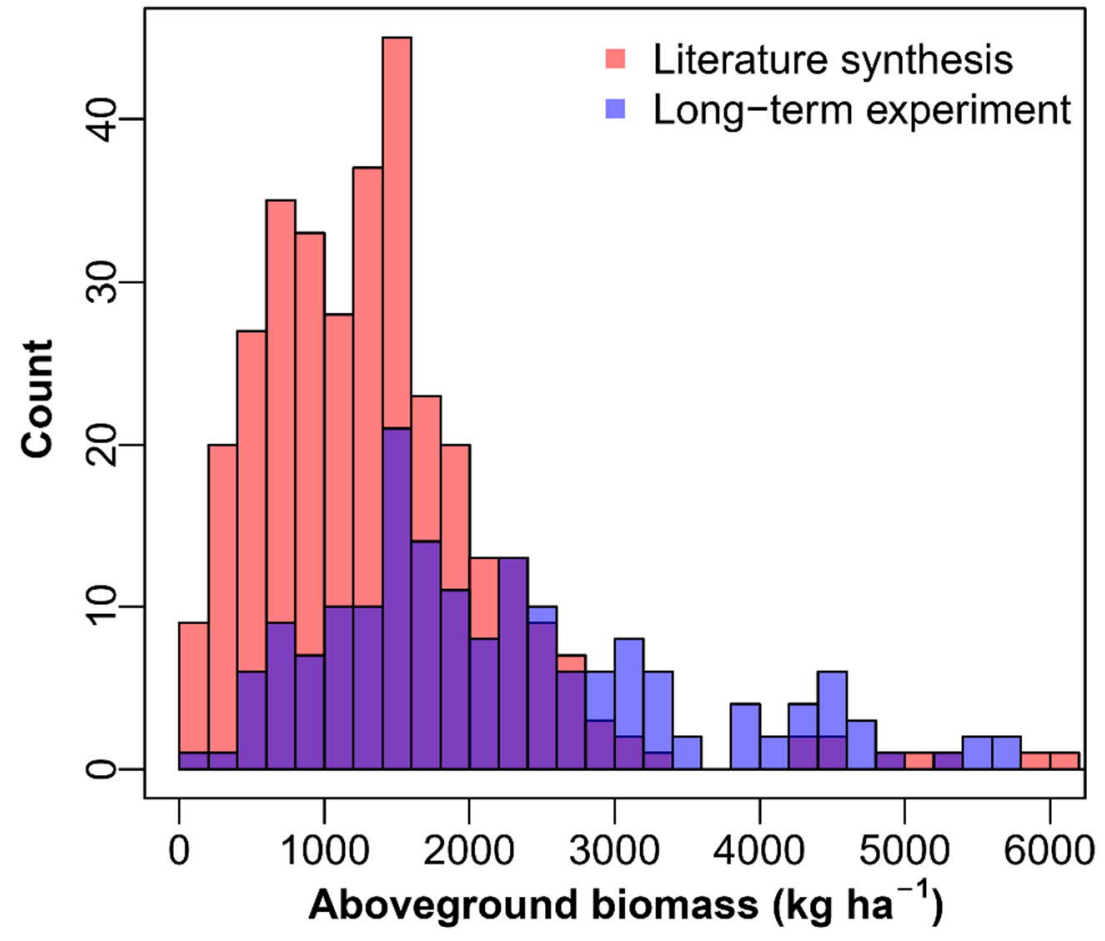

Figure S1. Histogram of aboveground biomass in Inner Mongolian grassland obtained from literature synthesis and the long-term field experiments. See Section 2.1 of the main MS for details. 

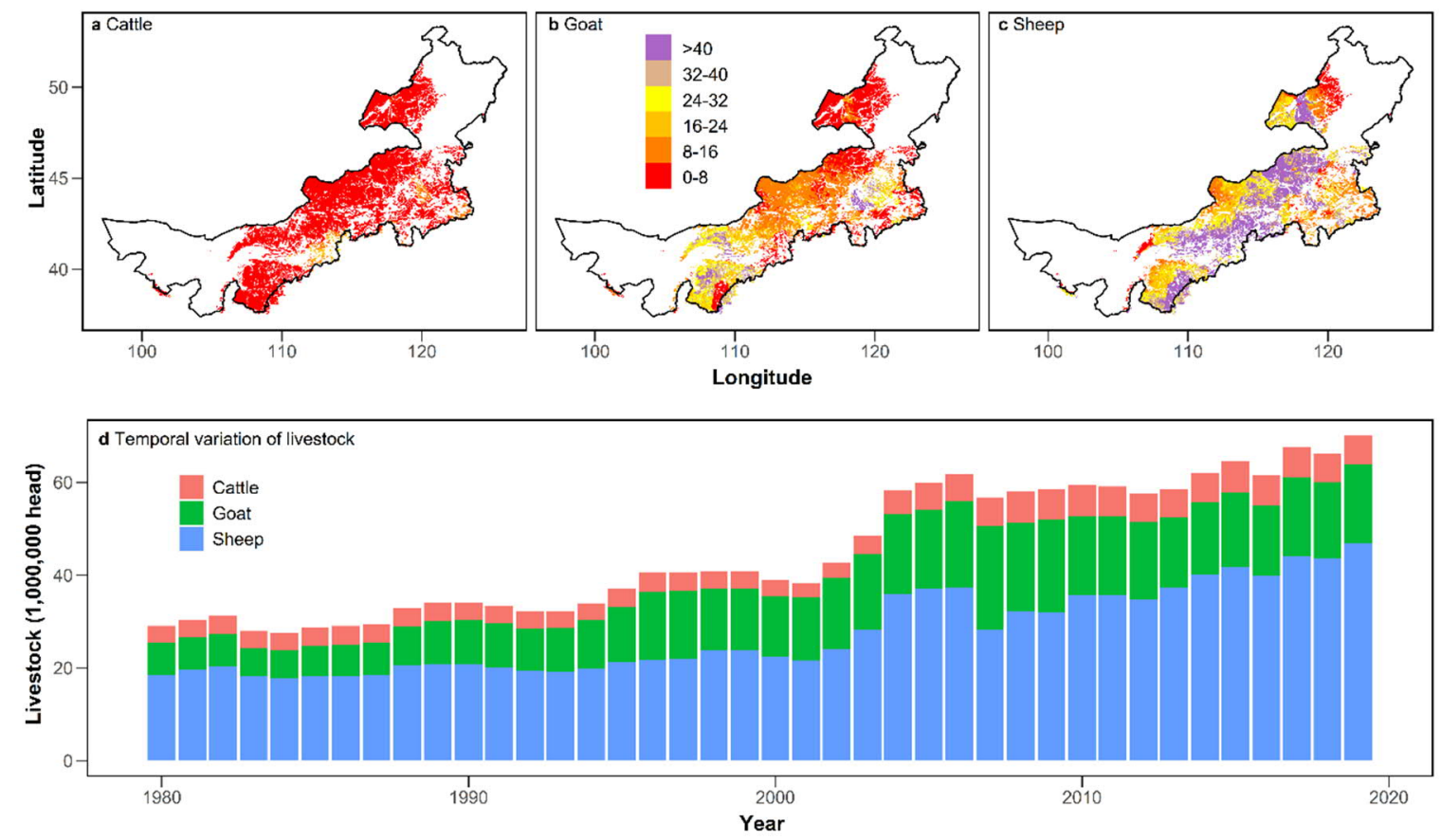

Figure S2. Spatiotemporal changes in livestock in Inner Mongolian grassland over the past four decades. The spatial patterns of cattle, goat and sheep (head $\mathrm{km}^{-2}$ ) were derived from Gilbert et al. (2018), who reported the global spatial patterns of livestock during 2010. The annual livestock data in Inner Mongolia is obtained from National Bureau of Statistics of China (https://data.stats.gov.cn/). 

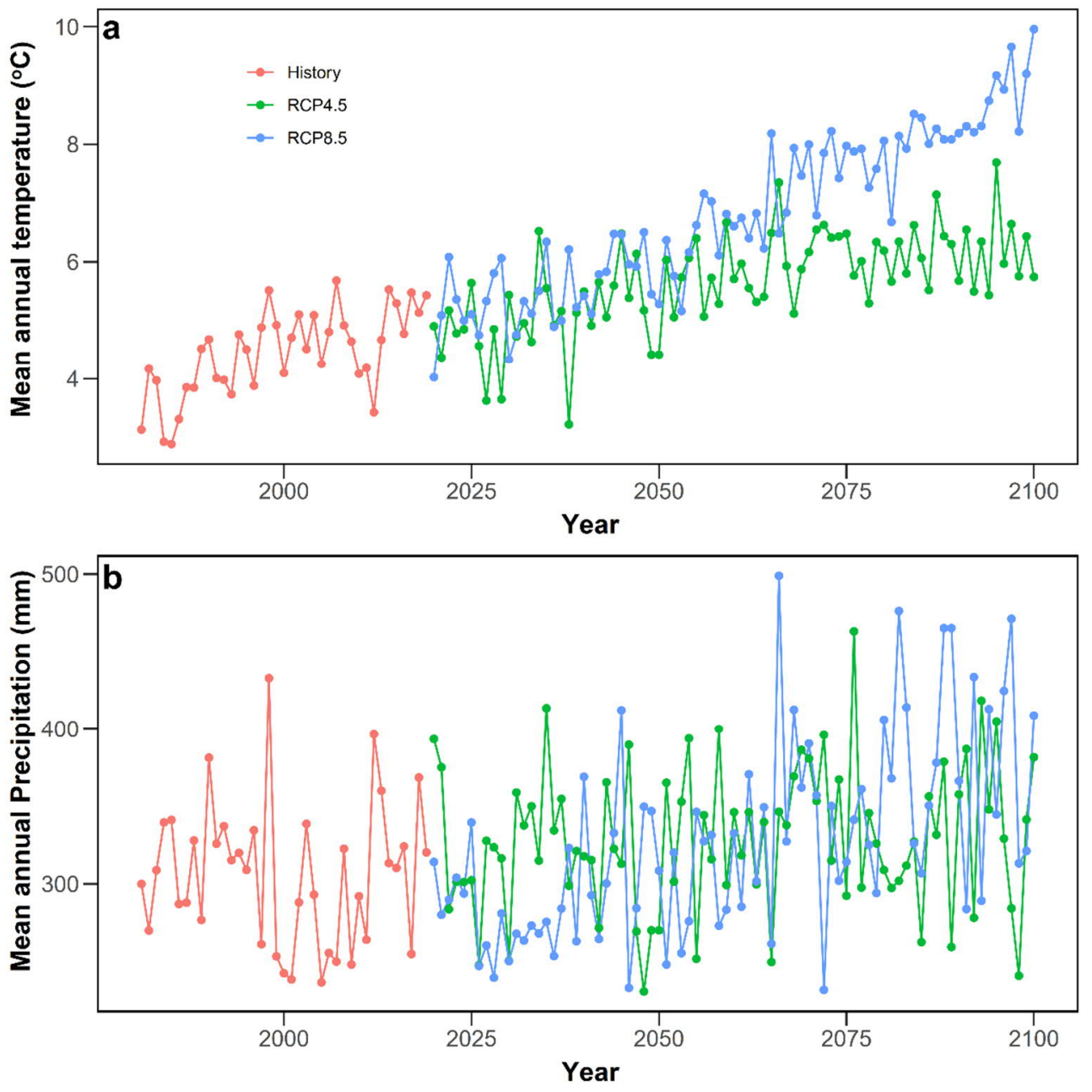

Figure S3. Mean annual temperature (a) and precipitation (b) in Inner Mongolian grasslands. The historical (1981-2019) temperature was determined from the daily climatic records obtained from the ground observations (Fig. 1b). Future (2020-2100) mean annual temperature were calculated from the projections by CESM1-BGC model using two representative concentration pathways (RCP4.5 and RCP8.5). The future climate data were derived from Karger et al. (2020). 

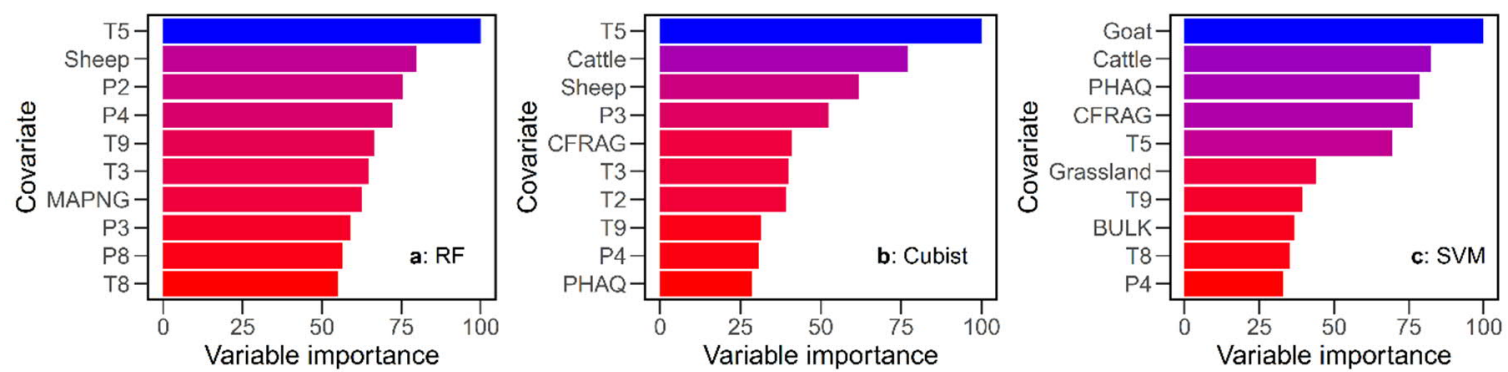

Figure S4. Variable importance indicated by the three individual machine learning models. a, random forest; $b$, Cubist; $c$, supporting vector machine. 


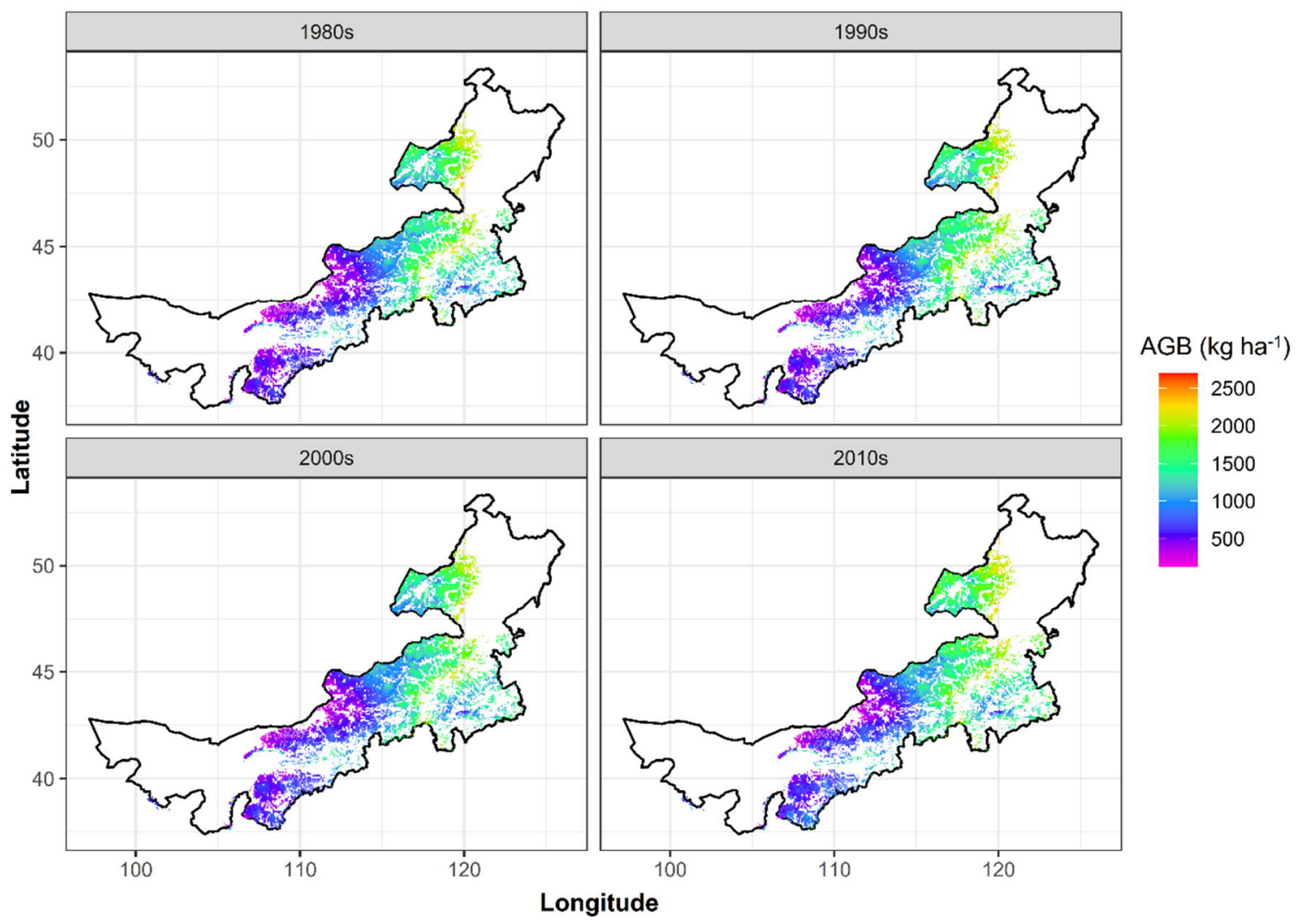

Figure S5. Spatial patterns of Inner Mongolian grassland aboveground biomass (AGB) estimated by the remote sensing derivations. The remote sensing based data are reproduced from the results published by Jiao et al. (2019). 


\section{Reference:}

Gilbert, M., G. Nicolas, G. Cinardi, T. P. Van Boeckel, S. O. Vanwambeke, G. W. Wint, and T. P. Robinson. 2018. Global distribution data for cattle, buffaloes, horses, sheep, goats, pigs, chickens and ducks in 2010. Scientific data 5:1-11.

Jiao, C. C., G. R. YU, Z. Chen, and N. P. He. 2019. A dataset for aboveground biomass of the northern temperate and Tibetan Plateau alpine grasslands in China, based on field investigation and remote sensing inversion (1982-2015). China Scientific Data 4.

Karger, D. N., D. R. Schmatz, G. Dettling, and N. E. Zimmermann. 2020. High-resolution monthly precipitation and temperature time series from 2006 to 2100 . Scientific data $7: 248$ 